\section{James Woudhuysen}

is director of forecasting at designers Seymour Powell in London and professor of innovation at De Montfort University in Leicester. In 1988, at Fitch, he co-directed Britain's first major study of ecommerce; in 1992, at the Henley Centre for Forecasting, he proposed that the Internet should be delivered over TV; between 1995 and 1997 he managed worldwide market intelligence for Philips consumer electronics in the Netherlands.

Keywords: e-commerce, fulfilment, innovation, Internet, brands

\section{Papers}

\section{E-fulfilment: The opportunities for the future: Part One}

\author{
James Woudhuysen,
}

Received (in revised form): 23 October 2000

\begin{abstract}
This, the first of two papers, examines the bad consumer experiences, high stakes, high hopes and deep fears that surround the picking and delivery of e-commerce 'tangibles' - in Britain, the EU and America alike. The paper attacks those who dwell on the merits of the electronic side of e-commerce and adopt an insouciant posture toward its physical aspects. It also suggests that while it is difficult to organise e-fulfilment on an economically viable basis, it is by no means impossible.
\end{abstract}

\section{Less than fulfilling experiences}

Fulfilment was once the discipline of corporate specialists in logistics; outside retailing, it was mostly about business-to-business (B2B) markets. Nowadays, however, thousands of British enthusiasts for the 'new economy' know the term, and hundreds can report experiences of business-to-consumer (B2C) e-commerce fulfilment that are less than fulfilling (Figure 1).

\begin{tabular}{|l|l|}
\hline Delivery delayed & \% respondents citing problems with e-tailers \\
\hline Had to chase up company & 15 \\
\hline Charged unexpected amount & 10 \\
\hline Goods arrived at the wrong time & 9 \\
\hline Wrong goods & 4 \\
\hline Payment messed up & 4 \\
\hline Goods damaged & 3 \\
\hline Goods sent to wrong place & 2 \\
\hline None of these & 62 \\
\hline
\end{tabular}

Figure 1: 'The last time you bought something and had it delivered, did any of the following occur?' Source: The Henley Centre (2000), 'Teleculture to e-culture', cited in Business 2.0, September, p.152 


\section{Good B2C means good service - fulfilment included}

\section{High stakes}

Despite or perhaps because of the unhappy consumer experiences of the past, the stakes in e-fulfilment have grown. In America, providing telephone and chatroom dialogues about the costs and schedules that surround 'shipping' is now essential to closing sales and improving customer service; while the business press insists that e-tailers build 'bulletproof' fulfilment systems in time to win a predicted $\$ 12 \mathrm{bn}$ of business over Christmas 2000 - 'a live-or-die season'.

In the UK it is the same story: tesco.com, which claims to be the world's largest online grocer, plans to pick food orders from no fewer than 300 of its 650 stores by January 2001, and sainsburystoyou.co.uk is to open the EU's largest dedicated grocery home-shopping centre at Park Royal, West London. Serving eight million people within the M25, this $£ 7-10 \mathrm{~m}$ investment will employ 500 people to pick 15,000 products from 80,000 square feet of space. Asda has announced plans to extend ASDA@home from within the M25 area to urban clusters in Lancashire, West Yorkshire, the Midlands and Glasgow, operating out of a quarter of its 240 stores by the end of 2001 and almost half by the end of 2002 .

\section{Conventional fulfilment is complex enough}

E-fulfilment involves high stakes because fulfilment in conventional retailing is already a complex affair. Conventional fulfilment means putting dozens of bulk orders on to warehouse pallets, into lorries, on to motorways and into shops that are often in tightly spaced urban areas. Matching inventory to demand seems beyond conventional retailers: whenever the author goes to the supermarkets they are out of Maille fish sauce, forcing him into what the retail sector calls a product substitution (Colman's).

Supermarket groceries, the largest retail market in Britain, are also the most challenging in terms of conventional fulfilment. Even more than other difficult sectors such as toys, grocers have to handle a range of product groups of widely differing sizes and shapes. There are also different sell-by dates and different temperature regimes to consider. The whole lot is handled by specialised regional distribution centres (RDCs), which focus on one or more product group (Figure 2).

\section{E-fulfilment is even more complex}

If conventional fulfilment is hard, B2C e-fulfilment is harder. It means making up thousands of relatively small, individual orders in boxes, and delivering them in vans on local, residential roads. Even if the shopper picks and packs groceries at the supermarket checkout and the grocer only delivers them, the grocer must charge $£ 3-5$ on every $£ 100$ of goods delivered — and yet still lose money on delivery — and run a fleet of liveried but subcontracted vans, each of which is equipped with temperature-controlled compartments or boxes and weighs 3.5 tonnes when loaded up.

When one goes to a shop, one does not notice or care who did what to make the shelves full. But when the consumer buys online, goods will be delivered by several kinds of firm (Figure 3). 


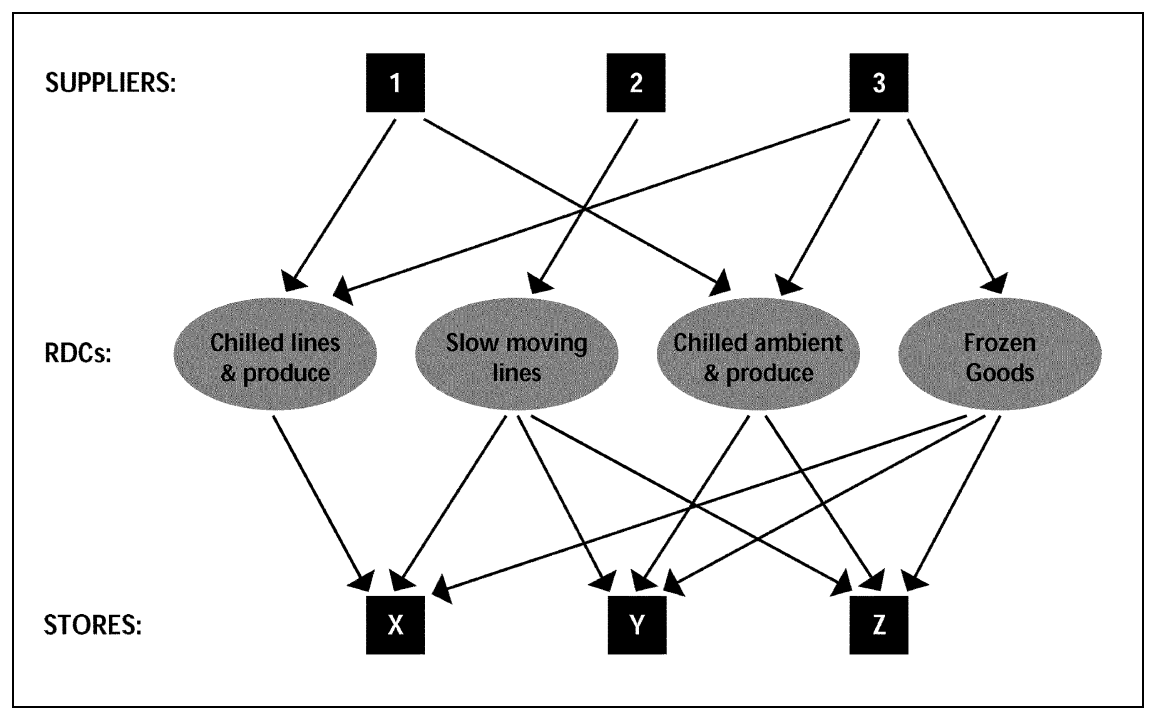

Figure 2: A typical UK supermarket's distribution chain Source: DT1 Retail Logistics Task Force (2000)

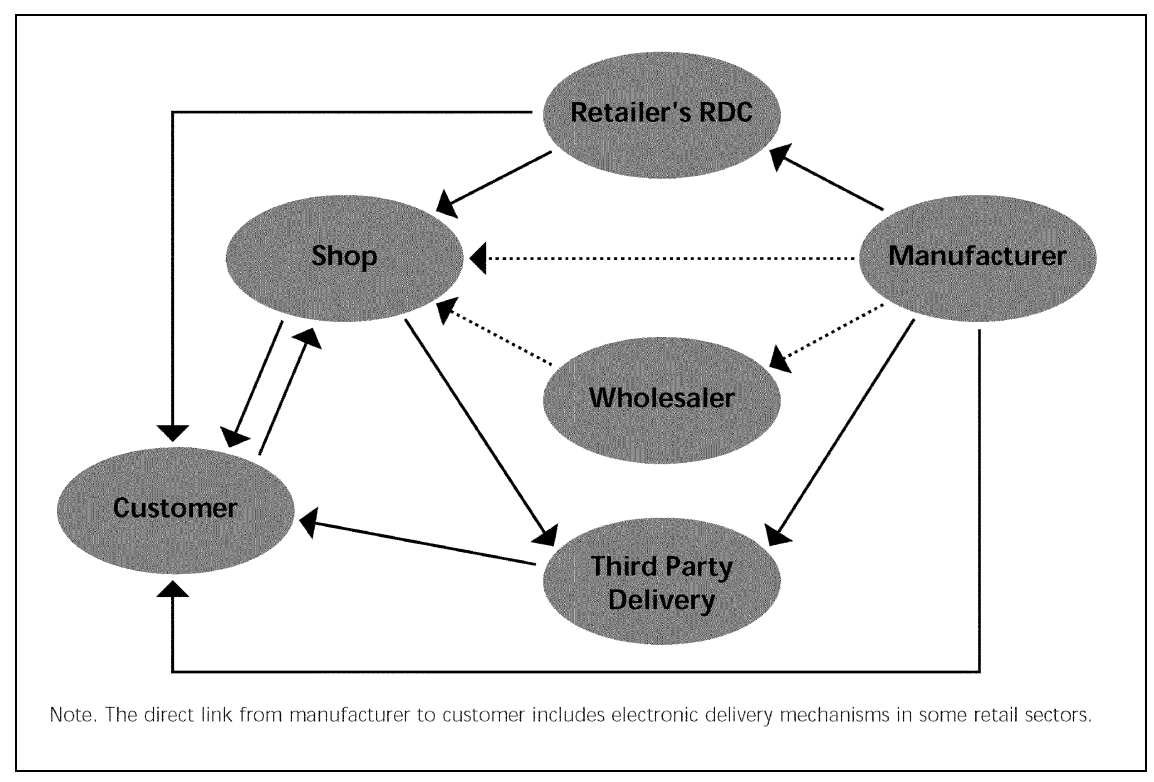

Figure 3: E-fulfilment means that consumers interface with up to four different parties Source: DT1 Retail Logistics Task Force (2000)

Fulfilment demands that B2C 'gets real'

\section{Fantasies put to the test}

Because of the consumer feelings that now surround online shopping, not just orders and product substitutions, but also questions and returns must all be handled more quickly and accurately in e-fulfilment than they are in conventional fulfilment. Also, data on customer histories in e-fulfilment are richer, more necessary to mine, but trickier than similar data in conventional fulfilment.

With B2C e-fulfilment, then, the 'virtual' realm of electronically assisted transactions and one-to-one marketing must be translated into the real world of transport vehicles, uniformed deliverers and robust product 


\section{Some management gurus are stuck on the screen ...}

\section{... but handling hard-edged products cannot be avoided}

packaging; general, location-independent cyberspace meets particular, location-dependent milieux with which even direct marketers, long keen on geography, are not always fully familiar; 'traffic', 'security' and 'storage' have their traditional meanings, not just their newer ones; and the fantasies of those who proclaim the death of distance, the weightless economy, or the merits of Britain 'living on thin air' are put to the test. ${ }^{2}$

This last point is important. In an influential article, the Boston Consulting Group (BCG) holds that, after a first generation of growth without profits ('landgrab'), e-commerce has entered a second 'defence versus capture' generation. Here pure navigators - the search engine Yahoo, the financial software company Quicken, the travel auctioneers Priceline.com, Microsoft CarPoint in cars — take the consumer's side ('affiliate' to the consumer) and triumph against their most powerful adversary, physical retailers. All that the latter can do is commit fully to e-commerce, 'expect the new business to cannibalise the old', and 'fulfil orders in whatever way is most efficient for the electronic business'.

For an article claiming to be 'Getting real about virtual commerce', this is a cavalier attitude to e-fulfilment. ${ }^{4}$ Thus though everyone knows that Amazon has set an international standard in e-fulfilment, we are told that it is set to win because it has 'broadened its offerings from books and CDs to movies to drugs to toys', and because 'its true business is navigation'. Equally Dell succeeds not because it is a byword for efulfilment, but because, we are told, its website provides 'comprehensive and genuinely unbiased navigation' to the products it does not make.

In BCG's 'Doomsday scenario', even their possession of rich, non-Web customer histories will not protect physical retailers from being 'demoted' by navigators to the role of distributor. Manufacturers also face doom: aided only by rich product information (relevant to mobile phones, software, hi-fi components, cars, kitchen knives - but not to groceries) or by branded Web-based experiences (Mattel's Barbie on broadband), manufacturers face their business being commoditised, or being 'forced to compete on product-specific characteristics such as cost, technology, and features' 6

How purely navigational a business this kind of e-commerce is! Here fulfilment, like 'product-specific characteristics', is merely a detail, and the planet belongs to electrons and their manipulators. But in the real world, interactive marketers must take fulfilment seriously.

\section{High hopes for consumers and transport firms}

As consumers, we are offered not just e-commerce nightmares, but also ecommerce utopias:

- the avoidance of supermarkets and the stress that goes with getting to and returning from them (never leaving the house...)

- price cuts because of the disintermediation of traditional retailers and middlemen and the formation of buyers' clubs

- a more direct and mutually beneficial relationship with manufacturers

- comparison shopping of the new, near-infinite choice aided by 'navigators' smart 'agents' and 'infomediaries' 


\section{Transport firms specialists stand to benefit from fulfilment contracts}

- entertaining screen-based shopping experiences, aided by the advent of broadband telecommunications and digital TV.

B2C e-commerce also recommends itself, of course, to transport and logistics companies. Indeed, if B2C e-commerce companies outsource their e-fulfilment to the freight transport sector, that sector's own B2B online exchanges could be used to improve capacity utilisation by filling lorries that are currently empty on their return journeys ('back haul'), aggregate consumer demand and serve it more efficiently, and streamline insurance, currency risk management and intermediate warehousing.

\section{High hopes for manufacturers and conventional retailers}

For manufacturers, too, $\mathrm{B} 2 \mathrm{C}$ e-commerce does at least hold out the promise of

- volume growth and economies of scale

- less need for packaging

- redressing the balance of consumer power away from retailers

- higher margins, but lower prices to consumers and a more direct relationship with them.

Finally, e-commerce just might help conventional retailers

- gain new customers beyond their existing geographical or demographic markets

- raise the average transaction value from existing customers

— stop their market share being eroded by rival e-commerce operators. ${ }^{7}$

Old EU retailers could triumph
Marks and Spencer already runs food@home, a home-shopping trial in South Buckinghamshire. Ironically, however, McKinsey Europe argues that firms such as M\&S, and also Fnac, can now do well because they have lagged behind the USA by a year or two:

'In Europe, if incumbent businesses can move fast enough they have a good chance of beating out the competition - both the local Internet pure plays and their big US brethren, which are now planning to expand across the Atlantic. ${ }^{,}$

Why? Because

- retailers such as Dixons (UK) or Groupe Arnault/Kingfisher in France already run ISPs

- Web hardware prices, ISP access charges and telecommunications tariffs are all falling

- Europe leads the USA in mobile telephony, and will shortly begin to adopt broadband. ${ }^{9}$

\section{High hopes for 'Euro-commerce'}

Altogether, 'Euro-commerce' could mean 35 million West Europeans spending $\$ 700$ each quarter in 2002 , giving a market size of $\$ 25 \mathrm{bn}$. And all 


\section{Intangibles represent an easy option}

incumbent EU retailers need do to tap into this market, it is said, is acquire small local players in different aspects of e-commerce - including specialists in logistics. They must "move quickly, master "clicks-andmortar" (or "clicks-and-bricks") integration, and manage consolidation in the on-line world'. ${ }^{10}$ Indeed, since Dutch multinational grocers Ahold paid $\$ 73 \mathrm{~m}$ for a 51 per cent stake in Peapod, an ailing American specialist in efulfilment, this perspective has seemed vindicated.

There are, then, high hopes in EU e-commerce. But to conclude this first paper, we turn to two of the more familiar fears which surround efulfilment:

- the fear that, even before any fulfilment takes place, selling tangible products online risks problems of sensory deprivation

- the fear that e-fulfilment faces intrinsic problems of economic viability.

\section{Fears: The problem of tangibles}

Many believe that an inability to see products in the flesh spells doom for 'tangibles' on the Web. Here DDL, a firm devoted to Internet investments, finance and research, makes a typical attack on 'pure play' Web retailers:

'For a company to survive as an e-tailer, it must have at least two things going in its favour. First, the product should be a commodity that does not require quite close scrutiny and secondly, volumes need to drive the bottom line as gross margins are not in the 30 per cent range. ${ }^{, 11}$

Yet millions of customers of the UK's $£ 8$ bn mail-order industry buy things without 'quite close scrutiny'. Beyond the usual suspects - books, CDs and computer equipment - tangibles are already bought off the page by the million.

True economies of scale may prove elusive. 'Perishables' present problems of refrigeration and distribution. Whatever the hopes of LVMH's Eluxury website or Luxlook.co, the bankruptcy of online jewellers Miadora.com suggests that luxury is about scarcity, elitism and shopping in the flesh, not the Internet. But tangibility, by itself, cannot be the reason so many e-tailers are now in trouble.

The realism of screen presentations is, anyway, growing all the time. In the end, the argument about sensory deprivation amounts to a complacent refusal to tackle the real problem with tangibles - that they even more difficult to 'fulfil' than intangibles.

\section{Fears: Problems of economic viability}

The snags recently met by America's new-born specialists in same-dayor-quicker e-commerce fulfilment have served to intensify fears about its general economic viability. Urbanfetch has discontinued its B2C operations, Kozmo has cancelled its plans for an initial public offering, HomeGrocer has been acquired by Webvan, and Webvan itself has slowed up the pace of its expansion in different US cities. Even allowing for the obvious differences between US and UK delivery, it is clear that new UK entrants to e-fulfilment - such as Peter Wright's portal and nationwide last-mile courier ZipRound, LM Solutions (groceries), Dressmart.co.uk 


\section{In logistics, God is on the side of the big battalions}

\section{Retailers will have to change to profit from B2C}

('brand-new shirts in two hours') and Wapitover.com (order by WAP phone) face an uphill struggle.

By contrast, Booz Allen \& Hamilton points out that slower, older and infinitely larger firms in 'traditional package delivery services' could do well. ${ }^{12}$ It observes that the US postal service (USPS) handles more than half the consumer catalogue-shopping shipments in America and 32 per cent of e-commerce ones. United Parcel Service (UPS), also a big player in catalogue shopping, takes 55 per cent of US B2C e-fulfilment, and could easily boost the 10 per cent of its revenues that come from this source. Meanwhile, Federal Express retains a 10 per cent share in both categories. While Booz concedes that the USPS does not perform sameday delivery, it notes that, in London, the Royal Mail can deliver Amazon.co.uk orders on the same day if they are received by noon. That the USPS plans to offer each of America's 120 million residential homes a free e-mail address underlines its continuing power.

\section{E-tailers struggle to rise from the ashes...}

Booz is also sanguine about the e-fulfilment offered by major retailers. North Carolina's Lowe's Food Stores, for example, offers kerbside pick-up at its local outlets, while Barnes \& Noble has launched same-day delivery in Manhattan. In addition, Booz believes that retailers with the greatest geographical spread of outlets are likely to do best out of m-commerce.

So far, so good. However, in the UK conventional retailing is highly cost-efficient - and about to become more so. Critics of B2C e-fulfilment are therefore entitled to ask: how much UK consumers would be prepared to pay extra to have all the work they put into visiting shops - especially supermarkets - done profitably by the retailer. McKinsey Europe certainly holds that retailers in Europe 'must change completely to handle multi-point delivery and an order-of-magnitude increase in the difficulty of handling returns ${ }^{13}$ McKinsey USA adds that while savings of up to 30 per cent are possible if the cost of long-distance telephone calls, data entry, teleserve operations and error correction is reduced or eliminated and the cycle time between order and delivery is cut significantly, the lack of a fully integrated order management system is such a problem that 'no leading [US] retailer has made the transition to total integration and automation of on-line and off-line orders - a failure that reflects not only the complexity but also the expense of the task'. And while speedy delivery to satisfy 'e-impulse' orders would be good, each missed delivery — the 'dark house' problem — adds as much as a full day to the fulfilment process. ${ }^{14}$ 'To post comfortable contributions on each transaction', McKinsey USA has most recently pronounced, means an average order size of at least $\$ 100$, a fulfilment cost of $\$ 10$ and preferably $\$ 5$, and gross margins of 'at least' 25 per cent. Anything else, and e-tailing will not be able to 'rise from the ashes.'.

\section{... while manufacturers struggle even more}

Of course, retailers can outsource fulfilment to specialists: delivery can be done by postal or courier services, or indeed by those mail-order firms 


\section{Manufacturers may find profits elusive}

\section{Express Dairies has a great network}

\section{Delivery points are another solution}

prepared to become 24/7, just-in-time subcontractors. But that, like the turn-the-volume-up-still-higher advertising expenditures now required of Web ventures, will erode retailer margins. For better or for worse, it also means putting the retailer's brand, and its precious customer data, in the hands of a third party.

In the UK, the EU online auction firm QXL has electronically integrated suppliers to its logistics partner Securicor Omega Express, so that ordered goods are taken directly from supplier to customer. Yet if this kind of compromise e-fulfilment can work for retailers, even it may prove too much for manufacturers.

Like online retailers, manufacturers face large promotional budgets if they are to make a name for themselves in e-commerce. Savings on packaging are likely to prove modest. Really what manufacturers might need is special products for selling over the Web; but in that case there are likely to be few economies of scale available. As for e-fulfilment proper, manufacturers have much less experience in its component disciplines than retailers.

At this bleak juncture, e-fulfilment looks like a going concern only to those transport and logistics firms lucky enough to strike a fairly shortlived deal with retailers that are either very naïve and likely to go bankrupt, or very clever and likely to organise fulfilment themselves (beyond its most commodity aspects) as soon as they have learnt how. But three factors could come to the rescue.

\section{Milkmen and collective delivery points to the rescue}

The first, very British factor is... the milkman. Express Dairies has 250 depots, 2,500 milk floats and visits 10 million homes six times a week. It plans to increase morning deliveries, and begin evening ones too. Express has invested $£ 3 \mathrm{~m}$ in M-box, which in June 2000 offered an 'end-to-end' service covering not just delivery, but the management of a complete system of e-fulfilment. Its partners include ParcelForce, Brann, Unilever and Unipower, the specialists in e-commerce behind tesco.com. M-box boasts that it can take orders from seven platforms: TV, Web and WAP, on the doorstep, mail, fax and hand-held scanner. It also says that it can receive and return goods by mail, parcel delivery, milk float, convenience store or motorbike.

A second factor that could rescue e-commerce from continual losses is this: once very expensive delivery to the home is replaced by schemes in which a whole number of households pick up orders from an intermediate 'collective delivery point' (CDP), the economics of e-fulfilment improve dramatically.

Whether staffed for security or, eventually, equipped with lockable containers, CDPs look like the way forward in British e-fulfilment practice. As the Retail Logistics Task Force of the Department of Trade and Industry (DTI) puts it, CDPs allow deliveries to be made

'at the optimum time for the retailer. The goods could be stored until it was convenient for the customer to collect them or the operator of the 
CDP could deliver as part of a local delivery round. This would also act as a central facility for the management of any returned goods. ${ }^{, 16}$

Types of CDP include

- arterial sheds; Brendan Flood's e-stop, Manchester, has $£ 5 \mathrm{~m}$ for 'hassle-free collection and returns' from drive-through light industrial buildings on main roads and at edge-of-town locations

- transport nodes, including airports, train stations, petrol stations and park-and-ride sites; Lynda Wallace's Dropzonel began delivering small packages for a $£ 1$ charge in the summer of 2000; backed by Jet petrol stations, Londis and Spar, Wallace plans 5,000 depots by autumn 2000, including video rental stores and off-licences, but centring on petrol stations

- local post offices, whether fully operational or recently closed (400 branches are closing each year and banks protest that they cannot find the $£ 150 \mathrm{~m}$ requested by the government for the subsidy of rural branches)

- leisure facilities, schools and recently closed bank branches

- workplaces

- confectioners, tobacconists and newsagents (CTNs).

\section{The stake has supported B2C fulfilment}

\section{With ingenuity, the 'last mile' can be conquered}

\section{State support comes in handy}

The third and final factor that might boost the economic viability of e-fulfilment is state intervention. In the UK, the DTI's study suggests that featherbedding by the state is already useful to UK grocers:

'Three of the retailers consulted were running their delivery services in parallel with social service contracts which provide grocery supplies to the elderly or housebound. These customers tend to be available to receive goods during the day and like to accept deliveries at a regular time each week. As a given local authority will award a contract for all such services to one organisation it guarantees a relatively high geographic concentration of delivery drops and a regular core delivery schedule to which commercial orders can be added., ${ }^{, 17}$

So long as public-private partnerships in e-fulfilment can be proved to lower welfare costs, it will have a future.

\section{Some interim conclusions}

Altogether, the basic economics of e-fulfilment are not nearly so fraught as they first appear. Thus, for instance, Mark Lunn's Homeport promises to move the number of 'drops' done by delivery van per hour from a loss-making five to a more lucrative 15: arriving by night, a Homeport employee waves a smart card over a wall-mounted box, then locks a reinforced cable from the box to a specially designed trunk full of deliveries. With ingenuity, the 'last mile' in the UK can be conquered.

Anyway it is picking, rather than the last mile, that is the main problem in e-fulfilment. If a typical grocery order delivery charge to a consumer is $£ 5$, typical grocery order picking costs currently amount to about $£ 13$. $^{18}$ 


\section{Pick from stores in the short term ...}

... and from
dedicated
warehouses in the
long term

Yet the signs are that grocers, who have the most difficult products to pick, can bring those costs down.

Though store-based order picking suffers from low catchment areas and high product substitutions, it requires little new investment. Thus tesco.com makes use of the scale of Tesco stores, hypermarkets and warehouses to bring prices down. It uses brand recognition to attract more customers, and acts as a new channel for distributing Tesco own-brand products - already a substantial revenue source for Tesco. No wonder tesco.com, which handles 60,000 60-item orders a week, hopes to be profitable by the end of 2000 , raising weekly sales from $£ 4 \mathrm{~m}$ to $£ 6 \mathrm{~m}$.

On the other hand, dedicated order picking is grander in scale and more reliable in execution, even if initial outlays are necessarily bigger. ${ }^{19}$ In the long term, it could be the best bet.

There is plenty of European consolidation still to take place in B2C fulfilment. Just like suppliers of Web integration services, suppliers of integrated e-fulfilment systems are not themselves that integrated: few can handle the full range of functions most clients want. But once these snags are ironed out, the barriers to B2C e-commerce - and B2C $\mathrm{m}$-commerce, for that matter - are likely to be political, not economic or technological.

The second part of this paper will discuss these less familiar but more important political barriers.

'Picking and delivering the goods, Part Two' will be published in Journal of Interactive Marketing, Vol. 2, No. 4.

\section{Acknowledgement}

The author is grateful to Kirsten A. Boehner of Strategos UK for her help with this paper.

\section{References}

1. 'Web stores try to keep shoppers bolting at the checkout point', Wall Street Journal, 10 October 2000; 'Cliffhanger Christmas', Business Week e-biz, 23 October 2000, p19.

2. See Cairncross, F. (1997) The Death of Distance: How the Communications Revolution Will Change Our Lives, Orion; Coyle, D. (1997) The Weightless World: Strategies for Managing the Digital Economy, Capstone Publishing; Leadbetter, C. (2000) Living on Thin Air: The New Economy, Penguin. Interestingly, the category of 'weightlessness' was first popularised by Federal Reserve Bank chairman Alan Greenspan in 1996.

3. Evans, T. and Wurster, P. (1999) 'Getting real about virtual commerce', Harvard Business Review, September-October.

4. It is, however, a consistent one. Back in 1997, the BCG consultants felt that delivery fleets, like other Old Economy paraphernalia ('a chain of stores' was one example), once 'served as formidable barriers to entry because they took years and heavy investment to build', but now could suddenly become expensive liabilities. See Evans, T. and Wurster, P. (1997) 'Strategy and the new economics of information', Harvard Business Review, September-October, quoted in Woudhuysen, J. (1999) Cult IT, Institute of Contemporary Arts.

5. Evans and Wurster, ref. 3 above

6. Ibid

7. DT1 Retail Logistics Task Force (2000) @ Your Service: Future Models of Retail Logistics, p. 10.

8. Cornet, P., Milcent, P. and Roussel, P.-Y. (2000) 'From e-commerce to Euro-commerce', The McKinsey Quarterly, No. 2, Europe. See http://mckinseyquarterly.com 
9. Ibid

10. Ibid

11. 'Sharp e-tailing edge needs defining', The Times, 19 August 2000

12. See Laseter, T., Houston, P., Chung, A., Byrne, S., Turner, M. and Devendran, A. (2000) 'The last mile to nowhere: Flaws and fallacies in Internet home-delivery schemes', Strategy and Business, Issue 20. See www.strategy-business.com.

13. Cornet et al., ref. 8.

14. Bhise, H., Farrell, D., Miller, H., Vanier, A. and Zainulbhai, A. (2000) 'The duel for the doorstep', The McKinsey Quarterly, No. 2. For more information on this paper, see the abstract on p. 289.

15. Barsh, J., Crawford, B. and Grosso, C. (2000) 'How e-tailing can rise from the ashes', The McKinsey Quarterly, No. 3.

16. DTI Retail Logistics Task Force, ref. 7, p. 21.

17. Ibid., p. 20.

18. Ibid.

19. Ibid., pp. $13-17$. 